\author{
Aleksandra ŚCIUBIDLO ${ }^{1}$ \\ Przemyslaw ŚCIUBIDLO ${ }^{2}$
}

\title{
WYKORZYSTANIE POPIOLÓW LOTNYCH W INŻYNIERII ŚRODOWISKA
}

\begin{abstract}
Synteza sorbentów z popiołów lotnych jest jednym z kierunków wykorzystania popiołów lotnych. Popiół lotny będący źródłem krzemu i glinu może być ekonomicznie i przyjaźnie dla środowiska wykorzystany do syntezy uporządkowanych materiałów mezoporowatych a otrzymane produkty $z$ odpadu energetycznego, jakim są popiołu lotne, są coraz szerzej wykorzystywane w przemyśle i inżynierii środowiska, jako adsorbenty, m.in. do oczyszczania gazów odlotowych m.in. $\mathrm{z} \mathrm{CO}$, NOx.

W przypadku zastosowania, jako źródła krzemu popiołu lotnego należy wydobyć krzem (w formie krzemianu sodu) z popiołu. Znane są dwie metody wydobycie krzemu, pierwsza z nich polega na uzyskaniu krzemianu sodu poprzez mieszanie popiołu w roztworze wodorotlenku sodu oraz druga polegająca na spiekaniu popiołu z wodorotlenkiem sodu. Druga metoda pozwala na wprowadzenie większej ilości krzemu do roztworu. W artykule przestawiono badania dot. syntezy mezoporowatego sita molekularnego MCM-41 oraz SBA-15.
\end{abstract}

Słowa kluczowe: popioły lotne, mezoporowate sita molekularne, SBA-15, MCM-41

\section{Wprowadzenie}

W Polsce w procesach wytwarzania energii elektrycznej wykorzystuje się głównie węgiel. Według GUS w 2014r. zużycie energii pierwotnej i pochodnej w przemyśle w Polsce wynosiło 4320,5 PJ, z czego 40,4\% tej energii wyprodukowano ze spalania węgla kamiennego a $14 \%$ z węgla brunatnego.

W 2014r. w Polsce 81\% energii elektrycznej produkowanej było z węgla a udział pozostałych nośników był niewielki. W 2014r wyprodukowano 3835,8 tys.t. popiołów lotnych z węgla, z czego 128,8 tys.t poddano odzyskowi a unieszkodliwiono 134,8 tys.t $\mathrm{w}$ tym 2,1 tys.t poddano składowaniu. Tymcza-

\footnotetext{
${ }^{1}$ Autor do korespondencji / corresponding author: Aleksandra Ściubidło, Politechnika Częstochowska, Instytut Zaawansowanych Technologii Energetycznych, Wydział Infrastruktury i Środowiska, ul. Dąbrowskiego 73, 42-200 Częstochowa, tel. 343250933, asciubidlo@is.pcz.czest.pl

2 Przemysław Ściubidło, Politechnika Częstochowska, Instytut Zaawansowanych Technologii Energetycznych, Wydział Infrastruktury i Środowiska, ul. Dąbrowskiego 73, 42-200 Częstochowa, psciubidlo@gmail.com
} 
sowo zmagazynowanych zostało 3520,6 tys. t. popiołów lotnych a 51,6 tys. $t$ przekazano innym odbiorcom. Natomiast odpady składowane (stan na koniec roku 2014) na terenach zakładów były na poziomie 26861,4 tys t. [1]

\section{Wykorzystanie popiołów lotnych w inżynierii środowiska}

Popiół lotny będący źródłem krzemu i glinu może być ekonomicznie i przyjaźnie dla środowiska wykorzystany do syntezy uporządkowanych materiałów mezoporowatych a otrzymane produkty z odpadu energetycznego, jakim są popiołu lotne, są coraz szerzej wykorzystywane w przemyśle $\mathrm{i}$ inżynierii środowiska, jako adsorbenty, m.in. do oczyszczania gazów odlotowych m.in. z $\mathrm{CO}_{2}$, NOx [2-8].

W przypadku zastosowania, jako źródła krzemu popiołu lotnego należy wydobyć krzem (w formie krzemianu sodu) z popiołu. Znane są dwie metody wydobycie krzemu, pierwsza z nich polega na uzyskaniu krzemianu sodu poprzez mieszanie popiołu $\mathrm{w}$ roztworze wodorotlenku sodu oraz druga polegająca na spiekaniu popiołu z wodorotlenkiem sodu. Druga metoda pozwala na wprowadzenie większej ilości krzemu do roztworu.

Jako pierwsi otrzymali mezoporowate glinokrzemiany z wyciągów z popiołów lotnych H.L.Chang i in. [9] w 1999 roku. Użyli oni do syntezy popiołu lotnego klasy $\mathrm{F}$ pochodzącego $\mathrm{z}$ Elektrowni w Pensylwanii o zawartości 56\% krzemu i 31\% glinu. Surfaktantem użytym w procesie syntezy sita MCM-41 był bromek cetylotrimetyloamonowy (CTAB). W pierwszym etapie procesu popiół lotny został zmieszany z NaOH w stosunku wagowym 1: 1,2 a następnie wytapiany w temperaturze $550^{\circ} \mathrm{C}$ przez 1 godzinę w przepływie powietrza $\mathrm{z}$ szybkością nagrzewania $1{ }^{\circ} \mathrm{C} / \mathrm{min}$. Po fuzji, zmielony proszek został zmieszany $\mathrm{z}$ wodą o stosunku wagowym 0,20 . Otrzymany roztwór mieszany był 1 dzień w temperaturze pokojowej i ciśnieniu otoczenia. W roztworze po oddzieleniu od osadu poprzez wirowanie, oznaczono zawartość Si i Al. Następnie $0,755 \mathrm{~g}$ surfaktantu CTAB zmieszano z 2,265 g wody destylowanej a po rozpuszczeniu dodano $0,5 \mathrm{ml} 4,96 \mathrm{~N} \mathrm{NH}_{4} \mathrm{OH}$ i rozcieńczono roztwór dodając $13,85 \mathrm{ml}$ wody. Tak przygotowany roztwór surfaktantu został dodany do $40 \mathrm{ml}$ roztwory otrzymanego z popiołu lotnego - supernatantu i wytrząsany był przez 30 minut. $\mathrm{PH}$ roztworu było na poziomie 12,8 . Roztwór następnie pozostawał $\mathrm{w}$ temperaturze $115^{\circ} \mathrm{C}$ w różnych czasach, w celu odparowania roztworu. Po przemyciu wodą destylowaną próbki suszono $\mathrm{w}$ temperaturze $60-80^{\circ} \mathrm{C}$ przez 12 godzin a następnie kalcynowano $\mathrm{w}$ temperaturze $540^{\circ} \mathrm{C}$ przez 7 godzin z szybkością nagrzewania $1{ }^{\circ} \mathrm{C} / \mathrm{min}$.

W 2001 roku P.Kumar $\mathrm{i}$ in. [10] przeprowadzili syntezę zarówno sita MCM-41 jak i SBA-15. Do badań użyty został popiół pochodzący z Elektrowni Nanao-Ota, charakteryzujący się $31 \%$ zawartością Si oraz $10 \%$ zawartością Al. W syntezie sita MCM-41 został użyty ten sam surfaktant, jakiego użył H.L.Chang $i$ in. [9] podobnie jak cały pierwszy etap syntezy tego sita. W przesą- 
czy oznaczono zawartości krzemu glinu i sodu, odpowiednio: 11000, 380, $35000 \mathrm{ppm}$. W dalszej kolejności $0,867 \mathrm{~g}$ CTAB zmieszano z $15 \mathrm{ml} \mathrm{H}_{2} \mathrm{O}$ i $0,75 \mathrm{~g}$ $\mathrm{NH}_{4} \mathrm{OH}$ aq., do którego dodano $38 \mathrm{ml}$ supernatantu-przesączu. Dla zapewnienia hydrotermalnych warunków procesu roztwór pozostawał przez 4 dni w temperaturze $97{ }^{\circ} \mathrm{C}$. PH roztworu regulowano w celu utrzymania wartości 10,2 kwasem octowym. W celu otrzymania sita Al-MCM-41 do roztworu dodano trimetyloaluminium $\left[\mathrm{Al}\left(\mathrm{CH}_{3}\right)_{3}\right]$. Otrzymany materiał po umyciu i wysuszeniu, kalcynowano w temperaturze $550{ }^{\circ} \mathrm{C}$ przez 8 godzin.

Do syntezy sita SBA-15 jako surfaktantu użyto trójblokowego kopolimeru EO ${ }_{20} \mathrm{PO}_{70} \mathrm{EO}_{20} .3,6 \mathrm{~g}$ kopolimeru rozpuszczono $\mathrm{w} 150 \mathrm{ml} 2 \mathrm{M} \mathrm{HCl}$ a następnie podczas mieszania dodano $40 \mathrm{ml}$ przesączu zawierającego 6,4 g krzemianu sodu $\mathrm{Na}_{2} \mathrm{SiO}_{3}$. Do tak przygotowanego roztworu dodano szybko $10 \mathrm{ml}$ stężonego $\mathrm{HCl}$ i $50 \mathrm{ml} \mathrm{H}_{2} \mathrm{O}$, po czym roztwór pozostawał $\mathrm{w}$ temperaturze pokojowej przez 1 dzień. Po tym okresie temperatura została podniesiona do $90{ }^{\circ} \mathrm{C}$ a próbkę pozostawiono $w$ tych warunkach przez 3 dni. Otrzymane próbki były kalcynowane w temperaturze $550{ }^{\circ} \mathrm{C}$ przez 6 godzin.

W 2006 roku K.S.Hui i in. [11] użył popiołu lotnego po wstępnej obróbce termicznej w temperaturze $120^{\circ} \mathrm{C}$ przez 30 minut o następującym składzie chemicznym: $17,8 \% \mathrm{Si}, 10,4 \% \mathrm{Al}$. W przeciwieństwie do poprzednich metod Hui użył roztwory wodorotlenku sodu. Zmieszał $30 \mathrm{~g}$ popiołu lotnego z $300 \mathrm{ml}$ $2 \mathrm{M} \mathrm{NaOH}$ i wytrząsał przez 4,5 godziny w temperaturze $100^{\circ} \mathrm{C}$. W przesączonych roztworach oznaczono zawartość $\mathrm{Si}$, Al odpowiednio: 5470 i $518 \mathrm{mg} / 1$. W dalszej części badań, w temperaturze $85^{\circ} \mathrm{C}$ do $82 \mathrm{ml}$ roztworu supernatantu dodano $1 \mathrm{~g} \mathrm{CTAB}$, podczas dalszego mieszania dodano $3,1 \mathrm{ml}$ octanu etylu. Po 10 minutach temperaturę ochłodzono do temperatury pokojowej. Do $10 \mathrm{ml}$ tak przygotowanego roztworu dodano $5.25 \mathrm{~N}$ kwas siarkowy VI w celu regulacji pH a próbki pozostały w temperaturze pokojowej jeszcze przez 24 godziny. Otrzymany materiał po przemyciu wodą destylowaną i wysuszeniu $\mathrm{w} 100^{\circ} \mathrm{C}$ przez 2 godziny kalcynowany był w $550^{\circ} \mathrm{C}$ przez 4 godziny z szybkością nagrzewania $1{ }^{\circ} \mathrm{C} / \mathrm{min}$.

W 2007 roku M.Halina i in. [12,13] po zmieleniu popiołu lotnego wybrał do syntezy ziarna o frakcji poniżej $200 \mu \mathrm{m}$ i wysuszone w temperaturze $373 \mathrm{~K}$ w atmosferze powietrza. Wykorzystując metodę przedstawioną przez Kumara [10] otrzymano przesącze, w których oznaczono Si, Al. odpowiednio: 10000 i 367 ppm. W drugiej części syntezy dokonano jednak pewnej modyfikacji. Surfaktant $\mathrm{CTAB}$ rozpuszczono $\mathrm{w}$ wodzie $\mathrm{z}$ etanolem $\mathrm{w}$ stosunku 1: 1 a następnie standardowo dodano amoniaku. Proces syntezy sita był tak prowadzony, aby stosunek molowy w żelu wyniósł $\left(\mathrm{SiO}_{2}: \mathrm{CTAB}: \mathrm{H}_{2} \mathrm{O}\right)=(1: 0,15: 170)$. Tak otrzymany roztwór był kilka godzin wytrząsany w temperaturze pokojowej. Autorzy w trzech próbkach ustawili różne $\mathrm{pH}$ wynoszące odpowiednio: 7,10 i 13. Po filtracji, myciu i wysuszeniu w temperaturze $373 \mathrm{~K}$ przez 12 godzin, próbki zostały wykalcynowane $\mathrm{w}$ temperaturze $823 \mathrm{~K}$ w atmosferze powietrza przez 6 godzin. 
Używając popiołu, jako źródła krzemu i glinu podjęto próby syntezy również sita SBA-16. W 2008 roku próbę taką podjął G.Chandrasekar i in. [14]. Przesącze zawierające wyciągi krzemu i glinu zostały przygotowane zgodnie $z$ procedurą Kumara [10]. Jako surfaktantu użyto trójblokowego polimeru o wzorze (EO106PO70EO106) o nazwie Pluronic F127. Synteza sita przebiegała w sposób następujący: $4 \mathrm{~g}$ surfaktantu rozpuszczono $150 \mathrm{~g} 2 \mathrm{M} \mathrm{HCl} \mathrm{i} \mathrm{wytrząsano}$ przez 4 godziny $\mathrm{w}$ temperaturze $40^{\circ} \mathrm{C}$, po czym dodano $12 \mathrm{~g}$ butanolu i kontynuowano wytrząsanie jeszcze przez godzinę. W celu poprawy struktury autorzy do roztworu dodano 1-2 g krzemianu sodu. Do tak przygotowanego roztworu po dodaniu $12 \mathrm{~g}$ stężonego $\mathrm{HCl}$ i $50 \mathrm{ml}$ wody, roztwór mieszano przez 24 godziny w temperaturze $40^{\circ} \mathrm{C}$. Następnie roztwory pozostawały w temperaturze $100^{\circ} \mathrm{C}$ przez 72 godziny. Po przesączeniu osady przemyto wodą, wysuszono i wykalcynowano $w$ temperaturze $550^{\circ} \mathrm{C}$ przez 24 godziny.

W następnej publikacji [15] autorzy Ci przedstawili syntezę sit MCM-41, SBA-15 i SBA-16 z użyciem popiołów dennych. Do badań wybrane zostały frakcje popiołów lotnych poniżej $200 \mu \mathrm{m}$ a wyciągi z popiołów zostały przygotowane w taki sam sposób jak w przypadku popiołów lotnych. Synteza MCM-41 przebiegała w sposób następujący: 1,2 g CTAB rozpuszczono w 15 g $\mathrm{H}_{2} \mathrm{O}$ i $1 \mathrm{~g} \mathrm{NH}_{4} \mathrm{OH}$ i mieszano przez 30 minut a po tym czasie do roztworu dodany został przesącz z popiołów dennych i kontynuowano mieszanie przez kolejne 2 godziny. Po wyregulowaniu $\mathrm{pH}$ na 10 przy użyciu kwasu octowego, roztwory pozostawiono $\mathrm{w}$ autoklawie przez 48 godzin $\mathrm{w}$ temperaturze $100{ }^{\circ} \mathrm{C}$. W przypadku syntezy sita SBA-15 autorzy przeprowadzili syntezę wykorzystując popiół denny zgodnie z procedura podaną przez Kumara [9] przy użyciu roztworów z popiołów lotnych. Natomiast wykorzystując procedurę syntezy sita SBA16 przeprowadzoną przez G.Chandrasekar [14] otrzymali SBA-16 wykorzystując popiół denny.

Kolejna publikacja tego autora [16] dotyczy syntezy sorbentów z popiołów lotnych pod kątem ich wykorzystania w procesie adsorpcji $\mathrm{CO}_{2}$. Po otrzymaniu sito SBA-15 zgodnie z procedurą przedstawioną we wcześniejszej publikacji autora [15], zostało zmodyfikowane poprzez impregnację iminami. W tym celu $1 \mathrm{~g}$ wykalcynowanego sita rozpuszczono w przygotowanym wcześniej roztworze, w którym zmieszano $1 \mathrm{~g}$ PEI( polietylenoiminy) z $8 \mathrm{~g}$ metanolu. Roztwór ten następnie mieszano przez 30 minut i suszono w temperaturze $70^{\circ} \mathrm{C}$ przez 16 godzin pod zmniejszonym ciśnieniem. Opisane badania stanowią punk wyjścia dla późniejszych prac prowadzonych w zakresie syntezy materiałów mezoporowatych z popiołów lotnych.

\section{Wykorzystanie popiołów lotnych w Polsce}

Dotychczasowe badania w Polsce dotyczyły syntezy zeolitów z popiołów lotnych [17-24] oraz możliwości ich wykorzystania w procesie adsorpcji dwutlenku węgla [25-28]. Poza zeolitami prowadzone były prace nad synteza mate- 
riałów mezoporowatych z popiołów lotnych [29-35] oraz możliwości ich wykorzystania w energetyce [35-37]. Do syntez materiałów mezoporowatych wykorzystywane były zarówno popioły lotne pochodzące z kotłów pyłowych jak i popioły pochodzące ze spalania w cyrkulacyjnej warstwie fluidalnej.

Wspomniani autorzy [4] do syntezy materiału mezoporowatego MCM-41 użyli popiołu, który charakteryzował się $51,39 \%$ zawartością $\mathrm{SiO}_{2}$ oraz $24,9 \%$ zawartością $\mathrm{Al}_{2} \mathrm{O}_{3}$ jak również 4,35\% zawartością wapnia. Zgodnie z klasyfikacją wg normy BN-79/6722-09 popiół ten został sklasyfikowany jako popiół krzemionkowy.

W pierwszym etapie syntezy autorzy przygotowali wyciąg z popiołu lotnego. W tym celu popiół zmieszano $\mathrm{z} \mathrm{NaOH}$ tak aby stosunek wagowy pozostał na poziomie $1: 1.2$, po czym mieszaninę mielono przez 2 godziny a następnie próbkę poddawano obróbce termicznej w $823 \mathrm{~K}$ przez 1 godzinę z szybkością nagrzewania $1 \mathrm{~K} / \mathrm{min}$. Po ochłodzeniu do temp. pokojowej powtórnie materiał zmielono i zmieszano z wodą w stosunku wagowym 1: 4 by w dalszej kolejności próbkę wytrząsać w temp. pokojowej przez 12 godzin. Próbka następnie została przefiltrowana.

W przygotowanym roztworze zawartość krzemu wynosiła $1,96 \times 10^{3} \mathrm{mg} / 1$ a glinu $8,4 \times 10^{2} \mathrm{mg} / \mathrm{l}$. Następnie do tak przygotowanego wyciągu roztworu krzemu dodano roztwór surfaktantu-matrycy. W tym celu CTAB rozpuszczono w wodzie destylowanej i dodano $\mathrm{NH}_{4} \mathrm{OHag}$ po czym dodano do supernatantu (wyciągu krzemu) tak, aby stosunek molowy w żelu wyniósł $\mathrm{SiO}_{2}: \mathrm{CTAB}: \mathrm{H}_{2} \mathrm{O}=$ $=1: 0.15: 170$. PH roztworu nastawiono na 11 przy użyciu $\mathrm{CH}_{3} \mathrm{COOH}$ i podczas ogrzewania w temp. 373K przez 4 dni regulowano kilkakrotnie $\mathrm{pH}$. Wykrystalizowaną próbkę następnie przefiltrowano, umyto przy użyciu wody destylowanej, aby usunąć nadmiar $\mathrm{NaOH}$ i wysuszono w temp. $373 \mathrm{~K}$ przez $24 \mathrm{~h}$. W celu usunięcia matrycy próbkę poddano kalcynacji w temp. 823K przez 2 godziny z szybkością nagrzewania $1 \mathrm{~K} / \mathrm{min}$.

W kolejnej publikacji Ci sami autorzy [5] przeprowadzili syntezę sita SBA-15, do syntezy którego jako surfaktantu użyto trójblokowego kopolimeru EO ${ }_{20} \mathrm{PO}_{70} \mathrm{EO}_{20}$. Kopolimer o masie $3,6 \mathrm{~g}$ rozpuszczono w $150 \mathrm{ml} 2 \mathrm{M} \mathrm{HCl}$ a następnie podczas mieszania dodano $200 \mathrm{ml}$ przesączu z popiołów lotnych uzyskanych podobnie jak przy syntezie sit MCM-41. Tak przygotowany roztwór pozostawał w temperaturze $90{ }^{\circ} \mathrm{C}$ pokojowej przez 96 godzin. Po tym czasie próbki przefiltrowano, przemyto wodą i suszono w temp $100{ }^{\circ} \mathrm{C}$ przez 8 godzin. Następnie otrzymane próbki były kalcynowane w temperaturze $550{ }^{\circ} \mathrm{C}$ przez 6 godzin.

\section{Podsumowanie}

Popiół lotny pochodzący ze spalania paliw stałych ze względu na znaczne zawartości krzemu i glinu, jest odpowiednim materiałem do syntezy sit mezoporowatych. Synteza sit mezoporowatych z popiołów lotnych umożliwia zagospo- 
darowanie popiołów. Modyfikacja popiołów w materiały mezoporowate pozwala na otrzymanie cennych sorbentów z odpadów energetycznych, jakim są popioły lotne oraz ich ponowne wykorzystanie w energetyce $\mathrm{i}$ inżynierii środowiska, jako adsorbenty, m.in. do oczyszczania gazów odlotowych m.in. z $\mathrm{CO}_{2}$, NOx.

Badania sfinansowano przez Narodowe Centrum Nauki na podstawie decyzji DEC-2011/03/B/ST8/05916.

\section{Literatura}

[1] GUS.

[2] X.Xu,C.Song,R.Wincek,J.M.Andresen,B.G.Miller,.W.Scaroni, 2003. Separation of $\mathrm{CO} 2$ from power plant flue gas using a novel $\mathrm{CO}_{2}$ "molecular basket" adsorbent. In: Prepr. Am. Chem. Soc. Div. Fuel Chem. 48, pp. 162-163.

[3] Fateme Rezaei, Ali A. Rownaghi, Saman Monjezi, Ryan P. Lively, and Christopher W. Jones, $\mathrm{SO}_{x} / \mathrm{NO}_{x}$ Removal from Flue Gas Streams by Solid Adsorbents: A Review of Current Challenges and Future Directions, Energy Fuels, 2015, 29 (9), pp. 5467-5486.

[4] A. Ściubidło, W. Nowak, Novel sorbents for flue gas purification, Journal of Power Technologies 92,(2),(2012), pp. 115-126.

[5] A. Ściubidło, W. Nowak Doczyszczanie spalin z tlenków azotu przy użyciu sorbentów z popiołów lotnych, Polska Inżynieria Środowiska Prace. Pod red. Marzenna Dudzińska, Artur Pawłowski. T.1, s. 299-305, Lublin, 2012.

[6] I. Majchrzak-Kucęba, A. Ściubidło, W. Nowak Fly Ash-Based Sorbents for PostCombustion Capture $\mathrm{CO}_{2}$. International Conference EuroCoalAsh. Monograph. Ed. Tomasz Szczygielski. Warsaw, 2008, s. 101-110.

[7] I.Majchrzak-Kucęba, A. Ściubidło, W. Nowak Mezoporowate materiały z popiołów lotnych do separacji dwutlenku węgla ze spalin, Popioły z energetyki. Monografia. Red. Tomasz Szczygielski, s. 85-94, Szczecin, 2007.

[8] W. Nowak, A. Ściubidło, Synteza mezoporowatego sita MCM-41 z popiołów lotnych do usuwania tlenków azotu, XVI Międzynarodowa Konferencja Popioły z energetyki, 21-24 październik 2009, Zakopane, s. 371-383.

[9] H.L. Chang, C.M. Chun, I. A. Aksay, W. H. Shih, Conversion of Fly Ash into Mesoporous Aluminosilicate, Ind. Eng. Chem. Res., 1999, 38 (3), pp. 973-977.

[10] P. Kumar, N. Mal, Y. Oumi, K. Yamanaa, T. Sano, Mesoporous materials prepared using coal fly ash as the silicon and aluminium source, J. Mater. Chem., 2001, 11, pp. 3285-3290.

[11] K. S. Hui , C. Y. Chao, Synthesis of MCM-41 from coal fly ash by a green approach: influence of synthesis pH, J Hazard Mater. 2006 Sep 21;137(2), pp. 1135-48.

[12] M. Halina, S. Ramesh, M. A. Yarmo, R. A. Kamarudin, Non-hydrothermal synthesis of mesoporous materials using sodium silicate from coal fly Ash, Materials Chemistry and Physics, Volume 101, Issues 2-3, 2007, pp. 344-351.

[13] M. Halina, C. Ramesh, B. Shahida, A. Y. Mohd., Processing of mesoporous silica materials (MCM-41) from coal fly ash, Journal of Materials Processing Technology Volume 186, Issues 1-3, 2007, pp. 8-13.

[14] Ch. Govindasamy, W. S. Ahn, Synthesis of cubic mesoporous silica and carbon using fly Ash, Journal of Non-Crystalline Solids, Volume 354, Issue 33, 2008, pp. 40274030 . 
[15] Ch. Govindasamy, K.S. You, J.W. Ahn, W.S. Ahn, Synthesis of hexagonal and cubic mesoporous silica using power plant bottom ash, Microporous and Mesoporous Materials, Volume 111, Issues 1-3, 2008, pp. 455-462.

[16] Ch. Govindasamy, W. J. Son, W. S. Ahn, Synthesis of mesoporous materials SBA-15 and CMK-3 from fly ash and their application for $\mathrm{CO}_{2}$ adsorption, Journal of Porous Materials, Volume 16, Number 5, 2008.

[17] I. Majchrzak-Kucęba, W. Nowak „Zeolity syntetyzowane z popiołów lotnych” - Fluidalne Spalanie Paliw w Energetyce, Materiały Konferencyjne, 2004, s. 207-217.

[18] I. Majchrzak-Kucęba, W. Nowak „Modyfikacja popiołów lotnych w materiałach zeolitowych" - XI Międzynarodowa Konferencja Popioły z energetyki, Materiały Konferencyjne Zakopane, 2004, s. 157-173.

[19] I. Majchrzak-Kucęba, W. Nowak „Application of model-free kinetics to the study of dehydratation of fly ash-based zeolite" - Thermochemica Acta 413 (2004), pp. 23-29.

[20]D. Bukalak, I. Majchrzak-Kucęba, W.Nowak, III Ogólnopolski Kongres Inżynierii Środowiska, Wpływa zawartości Si i Al w popiele lotnym na tworzenie się frakcji zeolitowych typu Na-P1, Materiały Konferencyjne, Lublin 2009, s. 35-47.

[21]D. Sztekler, I. Majchrzak-Kucęba, W. Nowak, III Ogólnopolski Kongres Inżynierii Środowiska, Analiza własności chemicznych popiołów lotnych pod kątem syntezy zeolitu Na-A, Materiały Konferencyjne, Lublin 2009, s. 316-320.

[22]A. Ściubidło, I. Majchrzak-Kucęba, W. Nowak, III Ogólnopolski Kongres Inżynierii Środowiska, Wpływ składu chemicznego popiołów lotnych na efektywność procesu syntezy zeolitów Na-X, Materiały Konferencyjne, Lublin 2009, s. 225-237.

[23] A. Ściubidło, W. Nowak. I. Majchrzak-Kucęba, 26th Annual International Pittsburgh Coal Conference, Characterization of zeolites from polish fly ashes, Materiały Konferencyjne, Pittsburgh, 20-23 September 2009.

[24] I. Majchrzak-Kucęba, A. Ściubidło, W. Nowak, 26th Annual International Pittsburgh Coal Conference, Studies on the properties of mesoporous materials derived from polish fly ashes, Materiały Konferencyjne, Pittsburgh, 20-23 September 2009.

[25] I. Majchrzak-Kucęba, W. Nowak „Properties of Zeolites Syntesized From Fly Ashes and Their Potential Application to CO2 Removal from Flue Gas" - Twenty-First Annual International Pittsburgh Coal Conference-Coal-Energy and the Environment, 2004.

[26] I. Majchrzak-Kucęba, W. Nowak „Studies of $\mathrm{CO}_{2}$ removal from flue gases using ash based Zeolites" - 8th International Conference on Circulating Fluidized Bed Technology VIII, Hangzhou, China, May 10-13, 2005, s. 748-754.

[27] I.Majchrzak-Kucęba, W.Nowak, A.Ściubidło, EuroCoalAsh, Sorbenty na bazie popiołów lotnych do wychwytywania $\mathrm{CO}_{2}$ po procesie spalania, Materiały Konferencyjne, Warszawa 2008, s. 101-110.

[28] I.Majchrzak-Kucęba, W.Nowak, 20th International Conference on Fluidized Bed Combustion, Development of Fly Ash-Based Sorbent To Capture $\mathrm{CO}_{2}$ From Flue Gas, 2009, pp. 596-603.

[29] I. Majchrzak-Kucęba, W. Nowak, P. Sil-Ibek, B. Kucharska „Mezoporowate sita molekularne z popiołów lotnych" - Fluidalne Spalanie Paliw w Energetyce, Materiały Konferencyjne, Politechnika Częstochowska 2005, s. 171-179.

[30]I. Majchrzak-Kucęba, W. Nowak „Modyfikacja popiołów lotnych w mezoporowate materiały" VII Ogólnopolska Konferencja Naukowo-Techniczna, Materiały Konferencyjne 2005 , s. $309-318$. 
[31]A. Ściubidło, I. Majchrzak-Kucęba, W. Nowak, EuroCoalAsh, Zagospodarowanie popiołów lotnych z polskich elektrowni i elektrociepłowni poprzez modyfikację popiołów w materiały mezoporowate, 2008, s. 163-180.

[32] I. Majchrzak-Kucęba, W. Nowak, 9thInternational Conference on Circulating Fluidized Beds in conjunction with the 4th International VGB Workshop Operating Experience with Fluidized Bed Firing Systems", "Synthesis and characterization of mesoporous materials from CFB-fly ash", Materiały Konferencyjne Hamburg, 2008 pp. 875-880.

[33] I. Majchrzak-Kucęba, W. Nowak, XVI Międzynarodowa Konferencja Popioły z energetyki, Modyfikacja popiołów lotnych w sorbenty i nanomateriały-doświadczenia laboratoryjne, Materiały Konferencyjne, Zakopane 2009, s. 217-225.

[34] A. Ściubidło, W. Nowak, XVI Międzynarodowa Konferencja Popioły z energetyki, Synteza mezoporowatego sita MCM-41 z popiołów lotnych do usuwania tlenków azotu, Materiały Konferencyjne, Zakopane 2009,s. 371-383.

[35] W. Nowak, I. Majchrzak-Kucęba, XVI Międzynarodowa Konferencja Popioły z energetyki, Sorbenty z popiołów lotnych dla energetyki, Materiały Konferencyjne, Zakopane 2009, s. 385-392.

[36] X.Xu, C. Song, R.Wincek, J.M.Andresen, B.G. Miller, A.W.Scaroni, 2003. Separation of $\mathrm{CO} 2$ from power plant flue gas using a novel $\mathrm{CO}_{2}$ "molecular basket" adsorbent. In: Prepr. Am. Chem. Soc. Div. Fuel Chem. 48, pp. 162-163.

[37]L.L. Sloss, Nitrogen Oxides Control Technology Fact Book, USA, 1992.

\section{UTILIZATION OF FLY ASH IN ENVIRONMENTAL ENGINEERING}

\section{S u m m a r y}

Synthesis of sorbent from fly ash is one of the methods of utilization fly ash. Fly ash is a source of silicon and aluminium can be economically and environmental-friendly sorbents- used for the synthesis of zeolites. The products obtained from waste energy are increasingly used in industry and environmental engineering, as adsorbents for flue gas cleaning from the $\mathrm{CO}_{2}, \mathrm{NO}_{\mathrm{X}}$. Silicon is extracted from fly ash in the form of sodium silicate. There are two methods of silicon extraction. In the first method, sodium silicate is obtained by mixing fly ash with sodium hydroxide solution.

The second method is sintering of fly ash with sodium hydroxide and allows for more silicon to be added to the solution. The paper presents the research on the synthesis of mesoporous molecular sieves MCM-41 and SBA-15.

Keywords: fly ash, mesoporous molecular sieve, SBA-15, MCM-41

Przestano do redakcji: $24.11 .2017 \mathrm{r}$.

Przyjęto do druku: 15.12.2017 r. 